\title{
Nonequilibrium Calcium Dynamics Regulate the Autonomous Firing Pattern of Rat Striatal Cholinergic Interneurons
}

\author{
Joshua A. Goldberg, ${ }^{1}$ Mark A. Teagarden, ${ }^{1}$ Robert C. Foehring, ${ }^{2}$ and Charles J. Wilson ${ }^{1}$ \\ ${ }^{1}$ Department of Biology, University of Texas at San Antonio, San Antonio, Texas 78249, and 2Department of Anatomy and Neurobiology, University of \\ Tennessee Health Science Center, Memphis, Tennessee 38163
}

\begin{abstract}
Striatal cholinergic interneurons discharge rhythmically in two patterns associated with different afterhyperpolarization timescales, each dictated by a different calcium-dependent potassium current. Single spiking depends on a medium-duration afterhyperpolarization (mAHP) generated by rapid SK currents that are associated with $\mathrm{N}$-type calcium channels. Periodic bursting is driven by a delayed and slowly decaying afterhyperpolarization (sAHP) current associated with L-type channels. Using calcium imaging we show that the calcium transients underlying these currents exhibit two corresponding timescales throughout the somatodendritic tree. This result is not consistent with spatial compartmentalization of calcium entering through the two calcium channels and acting on the two potassium currents, or with differences in channel gating kinetics of the calcium dependent potassium currents. Instead, we show that nonequilibrium dynamics of calcium redistribution among cytoplasmic binding sites with different calcium binding kinetics can give rise to multiple timescales within the same cytoplasmic volume. The resulting independence of mAHP and sAHP currents allows cytoplasmic calcium to control two different and incompatible firing patterns (single spiking or bursting and pausing), depending on whether calcium influx is pulsatile or sustained. During irregular firing, calcium entry at both timescales can be detected, suggesting that an interaction between the medium and slow calcium-dependent afterhyperpolarizations may underlie this firing pattern.
\end{abstract}

\section{Introduction}

Striatal cholinergic interneurons are autonomously active cells that may fire in regular single spiking, irregular, and rhythmic bursting patterns, in vivo and in slices (Bennett et al., 2000). In experimental models of Parkinson's disease, rhythmic firing is greatly increased (Raz et al., 1996). Previous studies of striatal cholinergic interneurons have revealed three independent oscillatory mechanisms in those neurons, any one of which is sufficient to produce a rhythmic firing pattern (Bennett et al., 2000; Wilson, 2005; Wilson and Goldberg, 2006). The regular single spiking pattern arises from the activation of a sequence of voltage-sensitive and $\mathrm{Ca}^{2+}$-sensitive currents. When hyperpolarized, activation of HCN current depolarizes the cell into the activation range of a persistent sodium current, which leads to firing of a single action potential (Bennett et al., 2000). Entry of $\mathrm{Ca}^{2+}$ through voltage-gated high-voltage-activated $\mathrm{Ca}^{2+}$ channels during the action potential activates $\mathrm{BK}$ and $\mathrm{SK} \mathrm{Ca}^{2+}$ dependent $\mathrm{K}^{+}$channels (Goldberg and Wilson, 2005). These contribute to spike repolarization and generate a powerful, brief, single-spike afterhyperpolarization. Recovery from the SK current component of the afterhyperpolarization (mAHP) is deter-

Received Nov. 21, 2008; revised April 22, 2009; accepted April 27, 2009

This work was funded by National Institutes of Health Grants NS37760 (to C.J.W.), NS33579 (to R.C.F.), and F32 NS050900 (to J.A.G.).

Correspondence should be addressed to Charles J. Wilson, Department of Biology, University of Texas at San Antonio, One UTSA Circle, San Antonio, TX 78249. E-mail: charles.wilson@utsa.edu.

D01:10.1523/JNEUROSCI.5582-08.2009

Copyright $\odot 2009$ Society for Neuroscience $\quad$ 0270-6474/09/298396-12\$15.00/0 mined by deactivation of $\mathrm{Ca}^{2+}$-dependent $\mathrm{K}^{+}$current and accelerated by HCN currents activated by the afterhyperpolarization. The slow bursting pattern is driven by a large TTX-insensitive membrane potential oscillation (Bennett and Wilson, 1999; Wilson and Goldberg, 2006). On the basis of their studies of driven firing, Wilson and Goldberg (2006) suggested that the slow oscillation and bursts may be generated by a lower-threshold dihydropyridine-sensitive $\mathrm{Ca}^{2+}$ current, presumably $\mathrm{Ca}_{\mathrm{V}} 1.3$. Goldberg and Wilson (2005) showed that $\mathrm{Ca}^{2+}$ entering the cell through this current does not activate SK channels, but instead has preferential access to a delayed, slowly activating and longlasting apamin-insensitive $\mathrm{Ca}^{2+}$-dependent $\mathrm{K}^{+}$current. They suggested that this slow afterhyperpolarization (sAHP) current phases the timing of spontaneous bursts and underlies the rhythmic bursting firing pattern seen in some cholinergic interneurons. Thus, $\mathrm{Ca}^{2+}$ entering the neuron via different $\mathrm{Ca}^{2+}$ channels has preferential access to two afterhyperpolarization currents with vastly different timescales that drive two very different firing patterns. It is puzzling how a single pool of cytoplasmic $\mathrm{Ca}^{2+}$ could underlie both of these $\mathrm{K}^{+}$currents with vastly different timescales, and that it could maintain the specificity of control by different $\mathrm{Ca}^{2+}$ currents.

In the experiments described here, we used $\mathrm{Ca}^{2+}$ imaging to determine whether $\mathrm{Ca}^{2+}$ entering the cell via spike-triggered or low-threshold $\mathrm{Ca}^{2+}$ currents is localized specifically in the soma or dendrites, and whether the patterns of $\mathrm{Ca}^{2+}$ concentration in various parts of the cell are altered during regular single spiking, rhythmic bursting, or irregular patterns of spontaneous autono- 

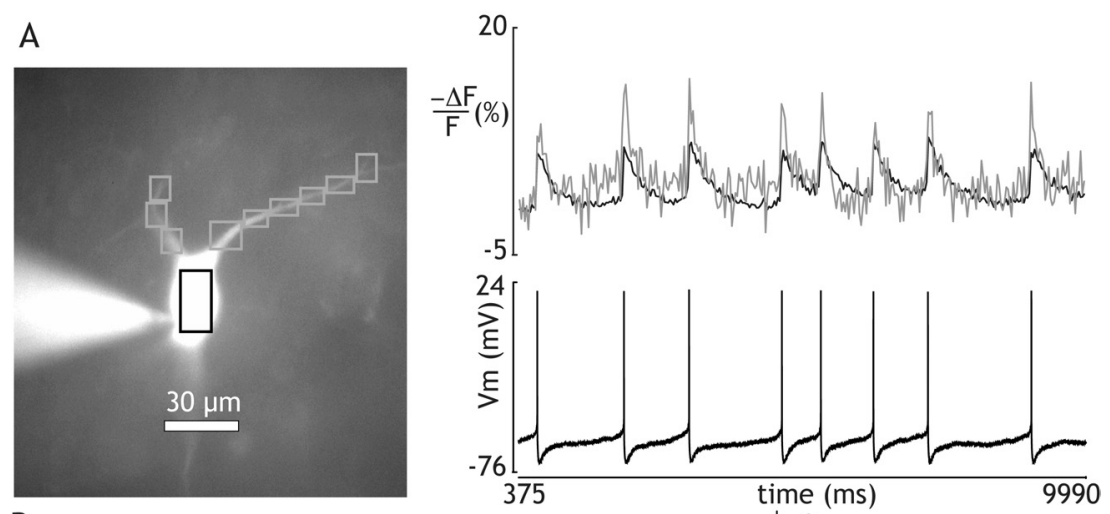

$$
\text { B }
$$
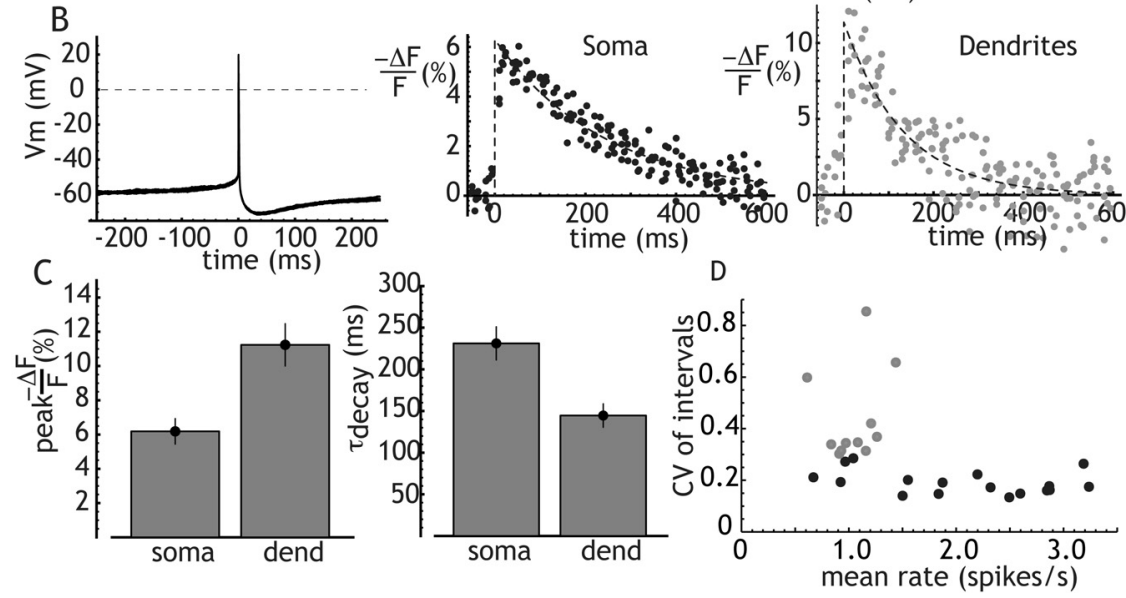

D

Figure 1. Action potential-triggered calcium influx in striatal cholinergic interneurons. $A$, Fura-2 fluorescence changes during spontaneous firing. The fura-2-filled neuron with somatic and dendritic regions of interest indicated, and simultaneous fluorescence changes in the soma and dendrites (above right) and somatic membrane potential (below). $\boldsymbol{B}$, High-temporal-resolution measurements of calcium transients by superimposition. From left to right, superimposed action potentials and somatic and dendritic calcium transients from eight consecutive spontaneous action potentials in the same cell as shown in $\boldsymbol{A}$. Best-fitting exponential decaying calcium transients accounting for the sampling function are shown as solid lines. $C$, Peak amplitudes and time constants for spike-triggered fura-2 calcium transients for spontaneous activity recorded in 28 neurons. Error bars are SEMs. D, Regularly and irregularly firing striatal cholinergic interneurons (same sample used in C). Cells firing at $1.5 / \mathrm{s}$ or faster exhibited very regular firing patterns, whereas cells with slower firing rates could fire irregularly. Points for cells considered variable for this sample ( $C V \geq 0.3)$ are colored gray.

mous activity. Our results indicate that there is no spatial pattern of compartmentalization of $\mathrm{Ca}^{2+}$, but that $\mathrm{Ca}^{2+}$ is instead compartmentalized in time by nonequilibrium dynamics of its binding to sites responsible for afterhyperpolarization currents with different timescales.

\section{Materials and Methods}

Slice and electrical recording procedures. Slices containing the striatum were prepared from Sprague Dawley rats aged 16-24 d using methods previously described (Bennett et al., 2000). All procedures were performed in accordance with the National Institutes of Health Guide for the Care and Use of Laboratory Animals and were approved by the University of Texas at San Antonio Institutional Animal Care and Use Committee. Briefly, animals were deeply anesthetized with ketamine-xylazine (90 $\mathrm{mg} / \mathrm{kg}$ and $10 \mathrm{mg} / \mathrm{kg}$ ) and perfused intracardially with $10-30 \mathrm{ml}$ of icecold artificial CSF (ACSF) modified by replacement of sodium with sucrose (Aghajanian and Rasmussen, 1989). The brains were removed and sectioned parasagittally at a thickness of $300 \mu \mathrm{m}$ and stored at room temperature in ACSF containing $125 \mathrm{~mm} \mathrm{NaCl}, 3.0 \mathrm{~mm} \mathrm{KCl}, 1.25 \mathrm{~mm}$ $\mathrm{NaH}_{2} \mathrm{PO}_{4}, 2 \mathrm{~mm} \mathrm{CaCl}, 1.5 \mathrm{~mm} \mathrm{MgCl}, 26 \mathrm{~mm} \mathrm{NaHCO}_{3}$, and $10 \mathrm{~mm}$ glucose, bubbled continuously with $95 \% \mathrm{O}_{2} / 5 \% \mathrm{CO}_{2}$. Slices were examined using an Olympus BX50WI with a $40 \times$ water-immersion objective. Cholinergic interneurons were identified by their large somatic diameters and radiating dendritic trees using differential interference optics under near-infrared illumination. Whole-cell recordings were obtained using a Neurodata IR-283 amplifier or with an Molecular Devices 700B amplifier. Patch electrodes were filled with a solution containing $119 \mathrm{~mm} \mathrm{~K}-\mathrm{MeSO}_{4}$, $12 \mathrm{~mm} \mathrm{KCl}, 1 \mathrm{~mm} \mathrm{MgCl}_{2}, 10 \mathrm{~mm}$ HEPES, 0.4 mм Na-GTP, 2 mм Na-ATP, and 0.05-0.2 mм fura- 2 or $0.2 \mathrm{~mm}$ bis-fura-2. Access resistances for current-clamp recordings were $\leq 50 \mathrm{M} \Omega$, and for voltage clamp were $\leq 25 \mathrm{M} \Omega$. Recordings were made at $32-35^{\circ} \mathrm{C}$. Signals were filtered at $5 \mathrm{kHz}$ and digitized at $10 \mathrm{kHz}$ or $20 \mathrm{kHz}$. Electrode capacitance and series resistance were compensated in current-clamp recordings using the active bridge circuits of the amplifier. For voltage-clamp experiments, electrode capacitance was compensated, but there was no compensation for whole-cell capacitance or series resistance. Voltage error due to series resistance was corrected off-line. All recordings were corrected for a $6 \mathrm{mV}$ liquid junction potential measured using the electrode solution as an estimate of the intracellular fluid.

Calcium imaging. After rupture of the membrane patch, at least $10 \mathrm{~min}$ was allowed for equilibration of the indicator between the electrode and the cytoplasm. Optical measurements were made using illumination at $380 \pm 15 \mathrm{~nm}$ and a cooled EEV37 frametransfer CCD camera (Photometrics). With the $40 \times$ ( 0.8 numerical aperture) objective, the camera pixel size was $0.32 \mu \mathrm{m}$, and these were binned into $4 \times 4$ pixel bins to achieve frame rates of $20-100 \mathrm{~Hz}$. Fluorescence signals were recorded while spontaneous activity was suppressed by injecting small hyperpolarizing currents into the soma to obtain an estimate of the rate of bleaching of the indicator, which was used to correct subsequent measurements. A best-fitting straight line was calculated for those background traces and subtracted from subsequent traces to correct for bleaching of indicator. Autofluorescence was also corrected by subtracting the fluorescence level of a nearby region not containing any indicator-labeled cell process. Optical data were obtained using a custom Windows-based program (CCD32, Jay Callaway, University of Tennessee, Memphis, TN).

Mathematical modeling. Numerical solutions to the equations for nonequilibrium calcium dynamics were obtained using xppaut (Ermentrout, 2002) using the QualRS integration method.

\section{Results}

\section{Spontaneous firing}

Calcium transients during spontaneous activity were studied in 28 fura-2-filled neurons selected from a larger sample on the basis of sustained spontaneous firing over the period required for analysis, and adequate fura-2 loading to allow measurable fluorescence changes. All cholinergic interneurons showed spontaneous activity in cell-attached recordings obtained before rupture of the membrane patch, but spontaneous firing was sometimes lost in the first 10-20 min of whole-cell recordings due to dialysis (Bennett and Wilson, 1999). As previously reported by Bennett et al. (2000), individual spontaneous action potentials were associated with calcium transients, which were smaller and longer lasting in the soma, and larger but briefer in the dendrites. An example is shown in Figure 1, $A$ and $B$. The timing of the transients suggests 
that they were triggered by the action potential, but the frame rate of calcium imaging $(50 \mathrm{~Hz}$ in this example) was insufficient to determine the precise relationship between action potentials and calcium transients. We used the method described by Teagarden et al. (2008) to improve the temporal resolution of the transients. Fluorescence samples surrounding the time of individual action potentials were extracted and superimposed, aligned with the action potential, whose timing was much more precisely known because of the high sampling rate of voltage. Because action potentials were asynchronous with the fluorescence frame rate, fluorescence samples from each action potential were asynchronous, and their superimposition effectively yielded a random sampling in time with an average sampling rate improved in proportion to the number of action potentials. An example showing the results for the eight action potentials in Figure $1 A$ is shown in Figure $1 B$. The voltage trajectory for the action potentials was similar, as shown in the left panel, in which the voltage traces are superimposed and aligned on the peak of the action potential. The superimposed samples from the somatic and dendritic fluorescence are shown in the middle and right panels of Figure $1 \mathrm{~B}$. The best-fitting exponential decay, adjusted for the sampling function [as described by Teagarden et al. (2008)] is superimposed on the samples in Figure $1 B$. Peak amplitudes and decay time constants of the fluorescence transients from each cell were measured from the sampling-corrected exponential. It should be noted that this procedure primarily corrects sampling errors in the rising phase of the transient, and does not appreciably influence the measurement of the decay time constant. The average peaks and decay time constants of somatic and dendritic fura-2 transients are shown in Figure 1C. Dendritic transients were approximately twice the amplitude of somatic ones (11.2 \pm $1.2 \%$ versus $5.8 \pm 0.5 \%$ ), and decayed slightly less than twice as fast $\left(\tau_{\text {decay }}=145 \pm 14 \mathrm{~ms}\right.$ vs $\left.231 \pm 20 \mathrm{~ms}\right)$. Firing rates for the sample of cells ranged from 0.6 to 3.2 spikes/s (mean 1.7, SD 0.8 spikes/s). They also varied in regularity of firing, with coefficients of variation (CVs) ranging from 0.13 to 0.85 (mean 0.29 , SD 0.17). In previous studies (Bennett and Wilson, 1999; Bennett et al., 2000), the analysis was restricted to the mechanisms of regular firing in striatal cholinergic neurons. In the current sample, 17 cells fit the criteria for regular firing used in the previous studies $(\mathrm{CV}<0.3)$, whereas 11 cells exhibited less regular firing. There was a strong relationship between regular firing and rate, as has previously been reported (Bennett and Wilson, 1999; Bennett et al., 2000), with most regularly firing cells also having mean rates of 1.5 spikes/s and higher. The sample of cells were thus divided into two groups, one with coefficients of variation $>0.3$, and another with coefficients $<0.3$, as shown in Figure $1 D$.

The spike-related calcium transients from regularly and irregularly firing neurons did not differ in amplitude or decay time constants. An example from both regular and irregular cells are shown in Figure $2 \mathrm{~B}$. As is typical for the irregularly firing cells in this sample and for cholinergic interneurons in general, irregular firing consisted of spike clusters and silent periods whose durations ranged from very irregular and unpredictable (as in Fig. 2) to very rhythmic bursting. Irregularly firing neurons, but not regularly firing cells, showed slow background fura-2 fluorescence changes that were apparently unrelated to action potentials. To measure these slow changes we obtained the average action potential-related calcium transients using the method shown in Figure 1, and fit those transients using an exponential function filtered by the sampling function set by the frame rate used for the measurements. We predicted the series of spiketriggered fluorescence transients for each cell by convolution of

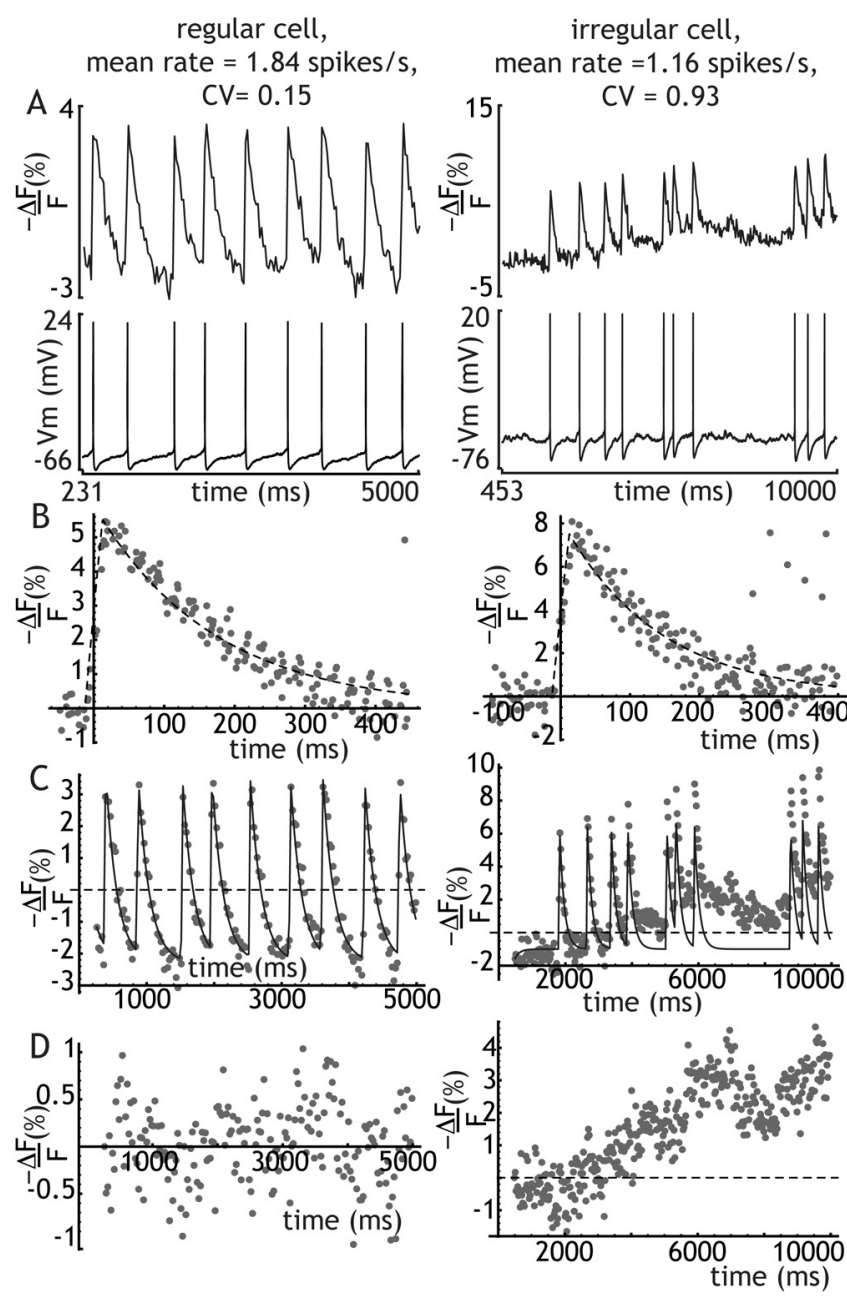

Figure 2. Spike-triggered calcium transients account for all intracellular calcium changes in regularly firing cells, but not in cells firing irregularly. $\boldsymbol{A}$, Spontaneous firing and associated changes in fura-2 fluorescence in a regularly firing cell (left) and an irregularly firing cell (right). Note slow changes in fluorescence in the irregularly firing cell, and the difference in scale. $\boldsymbol{B}$, Somatic calcium transients and best-fitting predictions of fluorescence change following action potential generation in the same cells shown in $\boldsymbol{A}$, calculated as in Figure 1. Note spike triggered transients are approximately the same size in both cells. $\boldsymbol{C}$, Predicted calcium transients based on convolution of the spike train and the best-fitting fluorescence transient shown in $\boldsymbol{B}$, superimposed on measured fluorescence changes. $\boldsymbol{D}$, Fura-2 fluorescence signals not accounted for by the fit shown in $\boldsymbol{C}$. Note difference of scales.

that single spike calcium-fluorescence change with a time series of unit impulses occurring at the times of action potential peaks. The predicted calcium transients calculated in this way are shown superimposed on the raw calcium fluorescence data in Figure 2C. Figure $2 D$ shows the residuals, which are the fluorescence changes that cannot be accounted for by action potentialtriggered calcium influx. For regularly firing neurons, this fit was always good, and yielded random residuals with small amplitudes and no slow pattern in time. For irregularly firing neurons, such as the one in Figure 2, there was a substantial slow component of the calcium signal that could not be accounted for by action potential-triggered calcium influx.

\section{Slow calcium transients during driven firing and bursting}

Slow changes in fluorescence could also be elicited by small but sustained depolarizing subthreshold current pulses, even when action potentials were blocked by application of $1 \mu \mathrm{M}$ TTX. These slow changes in calcium signal were characterized by rise and fall 


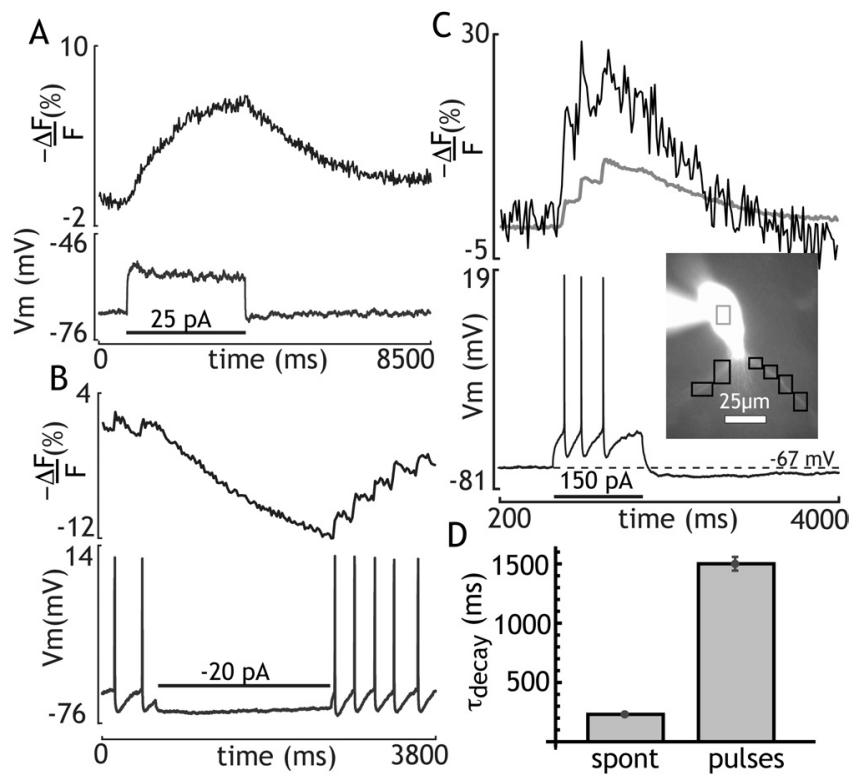

Figure 3. Slow changes in calcium-induced fluorescence associated with subthreshold membrane potential changes or driven firing. $\boldsymbol{A}$, Slow increase and decay in somatic calcium signal triggered by a subthreshold current pulse. $\boldsymbol{B}$, A slow decrease in somatic calcium signal associated with hyperpolarization, with a time course similar to the increase in $\boldsymbol{A}$. C, A burst of action potentials triggered by a depolarizing current pulse generated a accumulation of calcium in the soma (gray) and dendrites (black), which decayed on a slow timescale similar to that in $\boldsymbol{A}$ and $\boldsymbol{B}$. $\boldsymbol{D}$, Comparison of the somatic time constant of decay of calcium transients for spontaneous (spont) action potentials or suprathreshold depolarizing current pulses (as in $\boldsymbol{C}$ ) for a sample of 28 cells, 16 of which were studied using depolarizing steps. Calcium transients measured from long-duration current pulses, whether they evoked firing or not, decayed much more slowly than those evoked by spontaneous action potentials.

time constants much greater than the 100-250 ms time constant of decay of action potential-triggered calcium signals. An example showing the response to a subthreshold (25 pA) depolarizing current pulse in a cholinergic interneuron in control solution is shown in Figure $3 A$. A slow decrease in calcium with similar time course could be seen in most ( 5 of 6 cells tested) spontaneously firing cholinergic interneurons during hyperpolarization by applied current pulses. An example is shown in Figure $3 B$. Sixteen of the 28 cells of the sample were tested using larger depolarizing current pulses that triggered trains of 2-3 action potentials. All of these showed a slow rise and decay of calcium, as in the example shown in Figure 3C. The amplitudes and decay time constants of slow calcium transients triggered from suprathreshold current pulses were measured in these neurons, and compared with the time constants for the transients following spontaneous calcium currents in the entire sample. A comparison of decay time constants of the fura- 2 calcium signal following single spontaneous action potentials and these depolarizing current pulses is shown in Figure $3 D$. The amplitudes of spike-triggered calcium transients during spontaneous firing averaged $5.8 \%$ in the soma $(\mathrm{SD}=3.0 \%, n=28)$. Decay time constants averaged $231 \mathrm{~ms}$ ( $\mathrm{SD}=105 \mathrm{~ms}, n=28$ ). The amplitude of somatic fluorescence changes in response to brief trains of driven firing was approximately twice as large, averaging 9.8\% $(\mathrm{SD}=5.3 \%, n=16)$. In contrast to calcium changes during spontaneous firing, the time constant for decay of the slow calcium signal following depolarization-driven bursts was much longer, averaging 1506 $\mathrm{ms}(\mathrm{SD}=1407 \mathrm{~ms}, n=16)$. Slowly decaying calcium transients were seen after driven firing on prolonged current pulses in all cholinergic neurons studied, regardless of whether their sponta- neous activity was regular or irregular. Similar measurements were made in the dendrites, with the same outcome, except that decay time constants were shorter and amplitudes larger in the dendrites for both spontaneous and driven firing.

Another common firing pattern in cholinergic cells consists of irregular firing separated by spontaneous hyperpolarizing events. These hyperpolarizations have been shown to depend on hyperpolarization-activated potassium currents (Wilson, 2005). Two neurons in the sample presented here exhibited these spontaneous hyperpolarizations. In neither case was there any increase in calcium preceding those hyperpolarizations (data not shown), suggesting that they were not triggered by a calciumdependent process, but rather by the regenerative hyperpolarization mechanism as proposed previously (Wilson, 2005).

\section{Calcium-dependent medium afterhyperpolarization current}

A direct comparison of afterhyperpolarization currents with calcium entry was performed using voltage clamp. We measured afterhyperpolarization currents and calcium signals generated by single action potentials by applying brief $(2 \mathrm{~ms})$ depolarizing voltage pulses from a constant $-60 \mathrm{mV}$ baseline potential. Action potentials cannot be effectively clamped using our technique, so voltage control was lost during the brief pulse and action potential, and regained after the action currents and capacitive transients were complete, allowing measurement of afterhyperpolarization currents (Goldberg and Wilson, 2005). We expected larger calcium signals in the voltage-clamp experiments, so these experiments were performed using the lower affinity calcium indicator bis-fura-2.

The results of these experiments are shown in Figure 4. Single action potentials were followed by outward currents that were evident immediately after the end of the capacitive transient, and these were accompanied by calcium signals in both somata and dendrites (Fig. 4A). The decay time constants of the mAHP current, and the somatic and dendritic calcium signals (measured as in Fig. 1) are shown in Figure 4 B. Calcium decay time constants in somata averaged $267 \mathrm{~ms}$ ( $\mathrm{SD}=159 \mathrm{~ms}$ ). Dendritic decay time constants were faster than somatic ones, averaging $143 \mathrm{~ms}$ ( $\mathrm{SD}=$ $46 \mathrm{~ms}, t=3.09$, df $=7, p<0.02$ ). These calcium transients matched those seen using fura- 2 in the current-clamp recordings of spontaneous firing (Fig. 1C). The decay of the AHP current was adequately fit by a single exponential averaging $40 \mathrm{~ms}$ ( $\mathrm{SD}=$ $8 \mathrm{~ms}$ ), and was much faster than the calcium transients of either the soma or dendrites. Both the AHP current and the calcium signals were absent after blockade of sodium currents with $1 \mu \mathrm{M}$ TTX (Fig. 4A,D), indicating that the calcium influx was generated by the (incompletely clamped) action potential, not by the depolarizing voltage step used to trigger the action potential. TTX treatment also resulted in an outward shift in the holding current, consistent with its effects on the persistent $\mathrm{Na}^{+}$current at this holding potential $(-60 \mathrm{mV})$.

The medium afterhyperpolarization current in cholinergic interneurons has been previously shown to be dependent on apamin-sensitive SK channels specifically activated by calcium entering the cell via $\mathrm{N}$-type ( $\omega$-conotoxin GVIA-sensitive $\mathrm{Ca}_{\mathrm{V}} 2$ ) channels (Goldberg and Wilson, 2005). In agreement with those previous results, application of $\omega$-conotoxin GVIA $(1 \mu \mathrm{M})$ reliably reduced the $\mathrm{mAHP}$ (by $70 \%$ on average), and the dendritic and somatic calcium signal in all 10 cells tried by $48 \%$ and $47 \%$, respectively (Fig. $4 C, E)(p<0.01$ including correction for multiple comparisons), without any effect on the holding current. 


\section{Calcium dependence of the slow} afterhyperpolarization current

The sAHP current is the result of an apamin-insensitive calcium-dependent potassium current (Wilson and Goldberg, 2006). It is action potential independent and can be evoked by subthreshold depolarizations. When evoked this way, it is sensitive to dihydropyridines but not to $\omega$-conotoxin GVIA (Goldberg and Wilson, 2005). The sAHP can be elicited by small depolarizing voltage pulses that do not evoke action currents, and is not affected by TTX treatment. It shows a strong dependence on pulse duration, requiring pulses of at least $20 \mathrm{~ms}$ for detection, and is best evoked by pulses of $300 \mathrm{~ms}$ or longer (Wilson and Goldberg, 2006). To selectively activate the sAHP current, we applied $1 \mathrm{~s}$ voltage pulses of various amplitudes in the presence of TTX. The cells studied were the same ones used to study the effects of TTX on the medium AHP currents shown in Figure 4. Figure $5 \mathrm{~A}$ shows an example of tail currents and calcium transients evoked by $1 \mathrm{~s}$ depolarizing current steps. The outward tail current following the termination of the voltage pulse was measured $1 \mathrm{~s}$ after the termination of the current pulse, and this was used to calculate the voltage profile of activation of the tail current shown in Figure 5B. A bestfitting Boltzmann curve (shown as solid line) was used to calculate the voltage at which the current is half-maximal for each of the sample of 15 neurons. Voltage clamping cells for $1 \mathrm{~s}$ at very depolarized levels often damaged the cells, making it impossible to accurately fit the Boltzmann curve for the entire voltage range of interest, so half-activation voltages are intended only for purposes of comparing the curves, and not as an accurate measure of the voltage dependence of any calcium current. The comparison shows that calcium signal follows a similar voltage dependence as the calcium-dependent potassium current. The decay of calciuminduced fluorescence changes were fit with a single exponential, and were consistent across voltage steps, but the time constants for the onset and decay of cytoplasmic calcium differed. Time constants for somatic onset transients averaged $591 \mathrm{~ms}(\mathrm{SD}=194 \mathrm{~ms})$, whereas decays had time constants averaging $1710 \mathrm{~ms}$ (SD $677 \mathrm{~ms}$ ). As in the case of spike-triggered transients, calcium transients in the dendrites rose and fell faster than the soma. Dendritic onset time constants averaged $325 \mathrm{~ms}(\mathrm{SD}=110$ $\mathrm{ms})$, and decay time constants averaged $808 \mathrm{~ms}(\mathrm{SD}=411 \mathrm{~ms}$ ).

The time constants of decay of the calcium transients associated with the slow AHP were $\sim 6.4$ times longer in the soma and 5.7 times longer in the dendrites than observed for action potential-triggered transients (Fig. 5C). These decay time constants closely matched the decay rate of calcium signal observed for long current pulses in current-clamp experiments (Fig. 3), and the somatic calcium decay rate closely matched the decay rate of the slow AHP current. The voltage sensitivities of the calcium transients (measured $1 \mathrm{~s}$ after the end of the pulse) are shown in Figure $5 D$, along with their best-fitting curves. Somatic and dendritic calcium transients showed voltage sensitivities similar to that of the tail currents (Fig. 5D). Like the spike-triggered calcium transients associated with the medium AHP, calcium transients associated with the slow AHP were observed in both the soma and dendrites.

\section{The origin of the fast and slow calcium transients}

The above results provide no evidence for differential placement of fast transient or slow sustained calcium currents on the somata and dendrites of cholinergic interneurons. The preferential association of slow calcium concentration changes and the slow AHP 

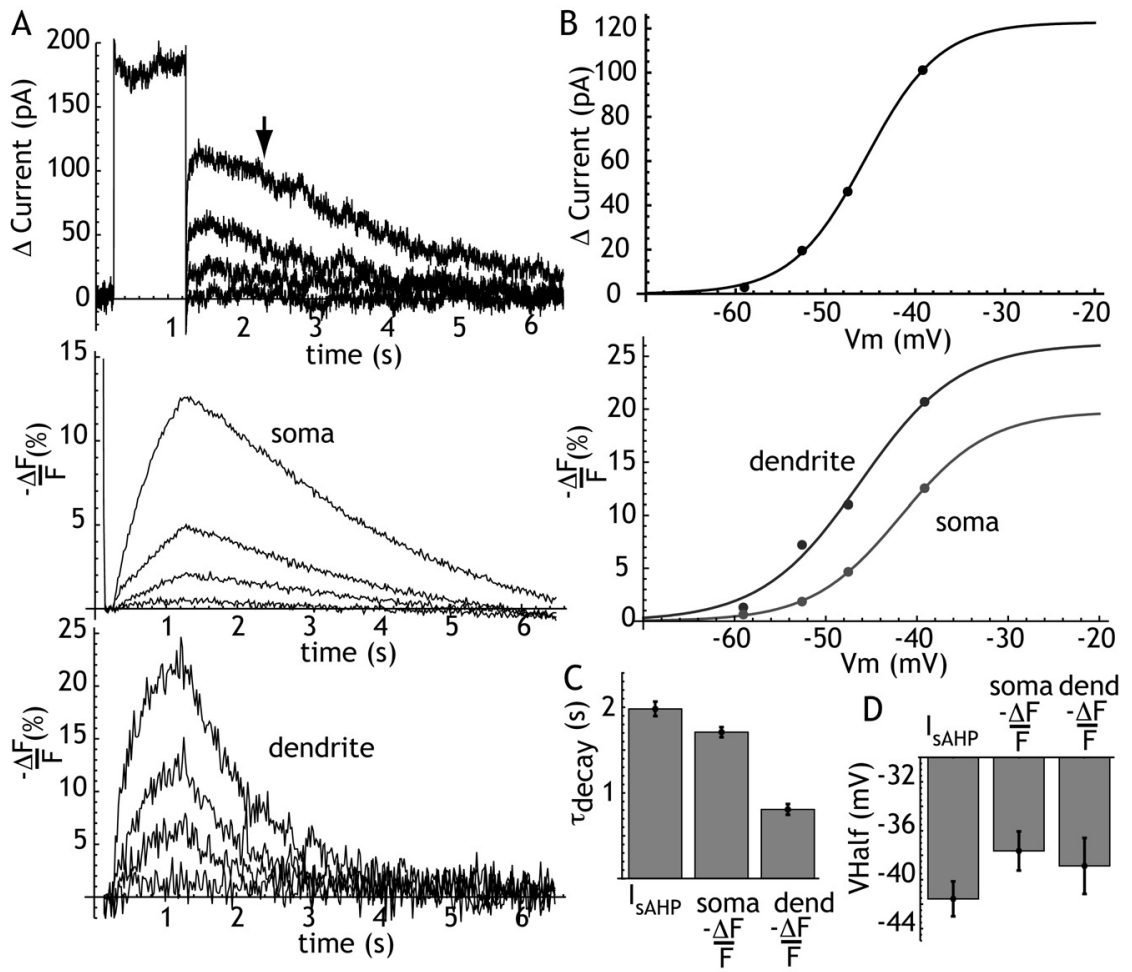

Figure 5. Action potential-independent slow afterhyperpolarization currents and calcium transients in voltage-clamp. $\boldsymbol{A}$, Depolarizing voltage pulses (1 s) applied in the presence of TTX generate slowly decaying outward tail currents and slow somatic and dendritic calcium fluorescence signals. Current and fluorescence traces are averages of five trials. $\boldsymbol{B}$, Voltage sensitivity of the tail current and somatic and dendritic fluorescence transients measured $1 \mathrm{~s}$ after the termination of the current pulse for the example shown in $\boldsymbol{A}$. Voltage steps were applied from a holding potential of $-68 \mathrm{mV}$. Lines are best-fitting Boltzmann function. C, Time constants for the decay of the tail current and fluorescence signal in the dendrites and soma. D, Half-activation voltages for the slow afterhyperpolarization current, and for the somatic and dendritic calcium signals (soma and dend, respectively), based on the best-fitting curves as shown in $\boldsymbol{B}$.

with L-type calcium channels and the fast transient calcium entry during action potentials with $\mathrm{N}$-type calcium channels and the medium AHP must rely on mechanisms present in both the soma and dendrites. Of course, it is possible that one of the currents is isolated on some distal dendritic or axonal location not observed in our experiments. It is also possible that the medium and slow calcium-dependent AHP ion channels are differentially distributed on the cell, but because calcium entering by both spiketriggered and subthreshold mechanisms are present in both the soma and in dendrites, this could not account for preferential activation of the mAHP and sAHP currents by spike-triggered and subthreshold calcium entry, respectively.

The dramatic difference in the time course of spike-triggered calcium transients and those arising from subthreshold membrane potential changes or long bursts of action potentials suggests another mechanism, whereby fast and slow calcium transients are differentially handled in all parts of the cell. We considered the possibility that the separation of calciumregulated AHP currents may rely on differences in calcium binding kinetics between the mAHP and sAHP binding sites, and that this could also account for the presence of to two distinctly different time constants of decay of calcium binding to fura. A shortening of the initial time course of calcium signals from transients was observed by others following intracellular introduction of the high-affinity but slow calcium buffer EGTA (Atluri and Regehr, 1996; Feller et al., 1996). The decay of the calcium indicator signal is usually attributed to removal of calcium from the cytoplasm, and its time constant is usually interpreted as reflecting the rate of transmembrane calcium pumps and sequestration in intracellular stores. In the EGTA experiments, addition of the slower buffer caused a more rapid initial decay of transient calcium signals, not by a change in the rate of calcium pumps, but by transfer of calcium from the calcium indicator to the slower cytoplasmic EGTA binding site (Atluri and Regehr, 1996; Feller et al., 1996). In those experiments, EGTA also created a much smaller and slower late component in the decay of calciuminduced indicator fluorescence. This slow decay was caused by the slowing of calcium removal from the cytoplasm by the presence of the slower EGTA binding site. Upon addition of an otherwise invisible slow calcium binding site on EGTA, the single time constant of calcium decay seen with a fast fluorescent indicator was replaced by two new time constants that reflected the kinetic differences between the EGTA and the endogenous buffers.

We reasoned that the sAHP binding site might constitute a slow high-affinity calcium binding site similar to EGTA, that could be responsible for shortening the fura calcium signal after an action potential, and also for the presence of the slow decay of fluorescence calcium signal seen after prolonged depolarizations. For very rapid transients like those following single action potentials, the fast time constant would predominate. Long transients would allow a near equilibrium between the fast and slow binding sites, and the slower time constant would be prominent. We used the method described by Markram et al. (1998) to model nonequilibrium calcium dynamics. As a simplification to represent the wide variety of calcium binding sites in the cytoplasm, we grouped them together into the minimum number of categories required to account for our results. We considered a system consisting of three classes of calcium binding sites, each of which could represent a family of calcium binding molecules that share similar kinetics and calcium affinities (Fig. 6A). Some of these might be calcium buffers (as in the case of fura-2), but they could also represent calcium binding sites of calcium-dependent enzymes or calcium-gated ion channels. Following the terminology of Markram et al. (1998), we call each of these binding sites a calcium reaction partner (RP). Because we observed two distinct time constants in the calcium signals from cholinergic interneurons $(\sim 250 \mathrm{~ms}$ for brief transients and 1.5-2.0 s for long ones), our model requires a minimum of two families of reaction partners differing in kinetics. The faster family of reaction partners (fast high-affinity RP) includes our calcium indicator (bis-fura-2), calmodulin, and an unknown variety of other fast highaffinity calcium reaction partners located in the cytoplasm. These vary in mobility from the highly diffusible fura- 2 to the fixed SK binding sites located on the plasma membrane. The effective mobility of this mix of calcium reaction partners was represented by a diffusion coefficient, but the SK binding site was represented separately as a fixed RP with kinetics and affinity similar to those of fura-2 (Naraghi et al., 1998). Be- 
cause the SK binding site differed from other members of the fast high-affinity RP group only in by its immobility and location in the cell, it did not introduce an additional time constant of calcium decay, but only altered the diffusional properties of the model.

The second reaction partner (slow high-affinity RP) was a slower and even higher-affinity binding site adjusted to match the time course of the slow AHP current [as in Fig. 5, and also Wilson and Goldberg (2006)]. Thus, we explicitly assumed that the kinetics of the slow AHP are determined by the kinetics of calcium binding to a diffusible cytoplasmic site responsible for the current. This was based on our observation that the slow calcium decay time constant (seen after long pulses) was similar to the decay time constant of the slow AHP current. Alternatives to this model include the possibility that slow kinetics of the current are caused by a long diffusion path between the site of calcium influx and the binding site, or a slow step between calcium binding and channel activation (Lancaster and Zucker, 1994; Sah and Clements, 1999; Abel et al., 2004). In our model, the slow decay of the sAHP is assumed to be a direct result of the slow release of calcium from the sAHP sensor site, which we refer to as the slow high-affinity RP. We begin by assuming that this binding site may be diffusible, but we will show that its diffusibility does not influence the outcome of the model.

Although only two calcium reaction partners are required to account for the two time constants of calcium signals, realistic calcium diffusion in the cytoplasm requires inclusion of a fast, lowaffinity immobile binding reaction partner (fast low-affinity RP). Diffusion of calcium away from the cell membrane and competition between buffers for calcium binding following brief calcium transients is critical to the time course of SK channel activation, and so we did not use the fast buffer approximation (e.g., Wagner and Keizer, 1994), but implemented the fast, low-affinity binding site as a separate reaction partner with its own kinetics. Parameters for this binding site were adapted from the endogenous calcium buffer described by Neher and Augustine (1992).

Bis-fura-2 is expected to compete with these other fast highaffinity reaction partners, and report the level of calcium binding by the entire group of reaction partners with similar kinetics. As a check on the validity of our assumption, we determined whether the result of the fit to slow AHP kinetics also produced realistic bis-fura-2 fluorescence transients. This is possible because the kinetics of the slow reaction partner determine not only the time course of the slow calcium decays and sAHP in our model, but
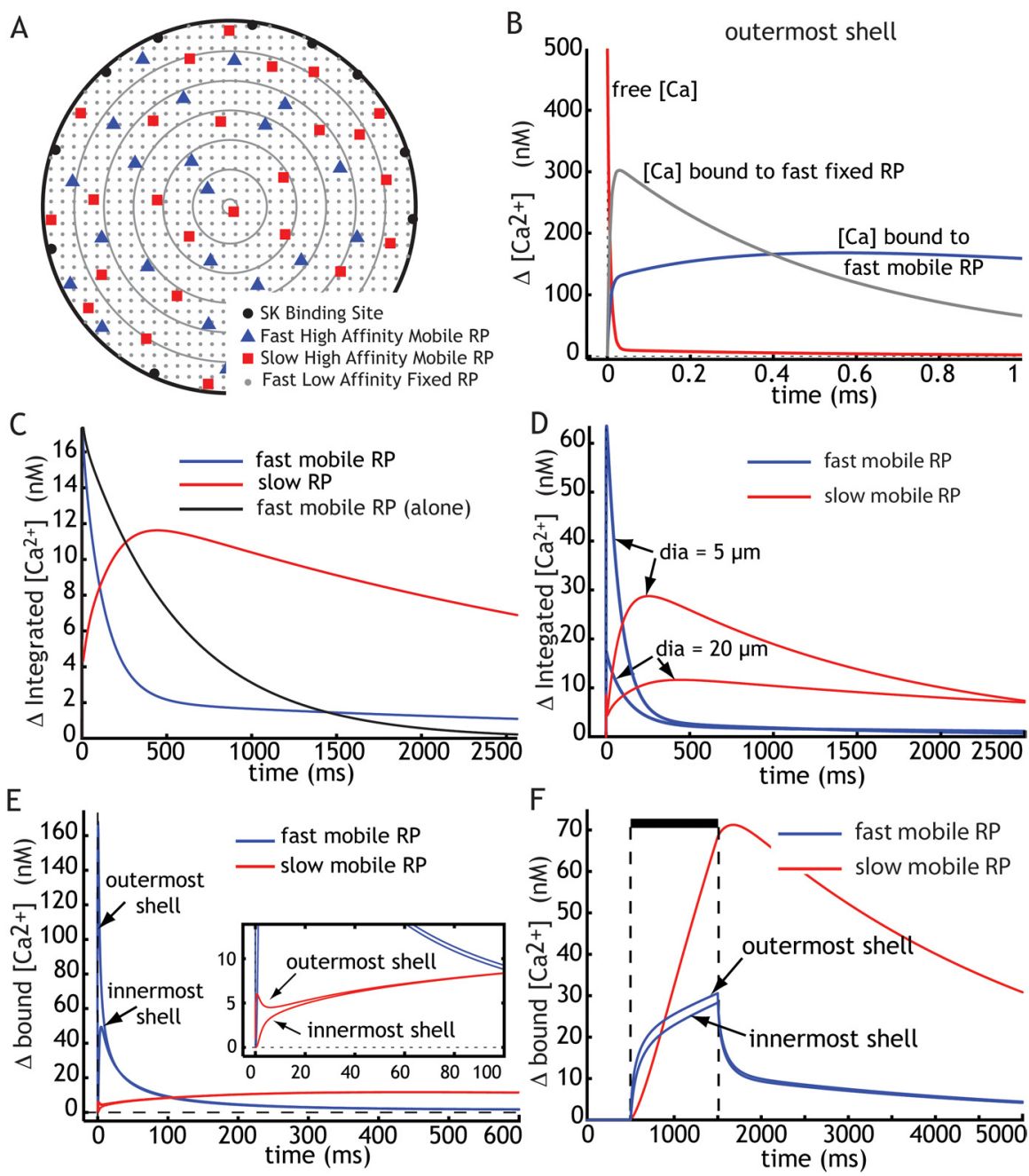

Figure 6. The cascade of calcium reaction partners is different for transient versus sustained calcium influx. A, A model process containing a fixed low-affinity RP, and fast and slow high-affinity mobile RP. The SK binding site is a subset of the fast high-affinity RP but fixed in the outermost diffusion shell. The fast high-affinity RP includes the exogenous calcium indicator. The SAHP calcium sensor is the slow RP. B, Fast movement of calcium between binding sites after an impulse calcium current places $500 \mathrm{~nm}$ free calcium in only the outermost shell. Free calcium goes to near-zero levels in the first $100 \mu \mathrm{s}$. Over the first $1 \mathrm{~ms}$, calcium begins to redistribute between reaction partners. The slow RP makes an insignificant contribution to binding in the first $1 \mathrm{~ms}$. C, Binding of calcium to the high-affinity mobile reaction partners, integrated across all shells. Total calcium binding to the fast mobile site calcium binding to the fast reaction partner in the absence of a slow buffer is shown for comparison. $\boldsymbol{D}$, Redistribution of calcium between fast and slow reaction partners depends on diameter (dia). The time constant of decay of calcium binding to the fast occupancy of the fast, but not the slow, RP depends on distance from the membrane. Binding to the slow RP occurs at a timescale slower than that required for spatial equilibration of calcium by diffusion of the fast RP. Inset shows the early phase of binding to of slow RP.F, Prolonged calcium influx produces preferential binding to the slow site if maintained longer than the time constan of redistribution among the fast and slow RPs. Binding to the slow RP peaks after the offset of the calcium current, even for long currents, and a slow, as well as a fast, component of decay is seen in the binding of calcium to the slow RP.

also the duration of the bis-fura-2 calcium binding transient seen after an action potential (as explained above).

The equations governing the three reaction-partner (plus SK) system are as follows:

$$
\begin{array}{r}
\frac{\partial\left[\mathrm{Ca}^{2+}\right]}{\partial t}=\operatorname{influx}-\frac{\nu_{\max } \times a\left[\mathrm{Ca}^{2+}\right]}{\nu\left[\mathrm{Ca}^{2+}\right]+k_{\mathrm{p}}} \\
-\frac{\partial[\mathrm{BCa}]_{\mathrm{i}}}{\partial t}-\frac{\partial[\mathrm{BCa}]_{\mathrm{f}}}{\partial t} \\
-\frac{\partial[\mathrm{BCa}]_{\mathrm{s}}}{\partial t}+D \frac{\partial^{2}\left[\mathrm{Ca}^{2+}\right]}{\partial r^{2}}
\end{array}
$$




$$
\begin{gathered}
\frac{\partial[\mathrm{BCa}]_{\mathrm{f}}}{\partial t}=\alpha_{\mathrm{f}}\left[\mathrm{Ca}^{2+}\right][\mathrm{B}]_{\mathrm{f}}-\beta_{\mathrm{f}}[\mathrm{BCa}]_{\mathrm{f}}+D_{\mathrm{rp}} \frac{\partial^{2}\left[\mathrm{Ca}^{2+}\right]}{\partial r^{2}} \\
\frac{\partial[\mathrm{BCa}]_{\mathrm{s}}}{\partial t}=\alpha_{\mathrm{s}}\left[\mathrm{Ca}^{2+}\right][\mathrm{B}]_{\mathrm{s}}-\beta_{\mathrm{s}}[\mathrm{BCa}]_{\mathrm{s}}+D_{\mathrm{rp}} \frac{\partial^{2}[\mathrm{BCa}]_{\mathrm{S}}}{\partial \mathrm{r}^{2}} \\
\frac{\partial[\mathrm{BCa}]_{\mathrm{i}}}{\partial t}=\alpha_{\mathrm{i}}\left[\mathrm{Ca}^{2+}\right]\left([\mathrm{BT}]_{\mathrm{i}}-[\mathrm{BCa}]_{\mathrm{i}}\right)-\beta_{\mathrm{i}}[\mathrm{BCa}]_{\mathrm{i}} \\
\frac{\partial[\mathrm{BCa}]_{\mathrm{SK}}}{\partial t}=\alpha_{\mathrm{SK}}\left[\mathrm{Ca}^{2+}\right]\left([\mathrm{BT}]_{\mathrm{SK}}-[\mathrm{BCa}]_{\mathrm{SK}}\right)-\beta_{\mathrm{SK}}[\mathrm{BCa}]_{\mathrm{SK}},
\end{gathered}
$$

in which $t$ is time, $r$ is distance from the center of the cell, [Ca $]_{\mathrm{i}}$ is the concentration of free calcium, $[\mathrm{BCa}]_{\mathrm{i}}$ is the concentration of calcium bound to the immobile low-affinity reaction partner, and $[\mathrm{BTT}]_{\mathrm{i}}$ is the total concentration (both calcium bound and unbound) of the immobile reaction partner. $[\mathrm{BCa}]_{\mathrm{f}}$ is the concentration of calcium bound to the fast mobile high-affinity reaction partner, $[\mathrm{B}]_{\mathrm{f}}$ is the concentration of unbound reaction partner, and likewise for the slow reaction partner $[\mathrm{B}]_{\mathrm{s}}[\mathrm{BCa}]_{\mathrm{SK}}$ is the concentration of SK binding sites occupied by calcium, and $[\mathrm{BT}]_{\mathrm{SK}}$ is the concentration of SK binding sites in the outermost shell. SK binding sites were restricted to the outermost cytoplasmic shell. The calcium influx term is in units of $\mathrm{nm} / \mathrm{ms}$, and is the transmembrane calcium flux through calcium current, normalized by the cell volume. The calcium pump is characterized by a maximum rate $v_{\max }$ and a dissociation constant $k_{\mathrm{p}}$, and produces a change in calcium concentration scaled by the surface-area-tovolume ratio $(a / v)$. $D$ is the diffusion coefficient of free calcium in the absence of binding sites, and $D_{\mathrm{rp}}$ is the diffusion coefficient of the mobile calcium reaction partners. The on rates and off rates for each of the reaction partners are given as $\alpha$ and $\beta$ for each. The spatial gradients of calcium and of both the bound and unbound reaction partners were approximated by evaluation of the equations in each of 40 concentric shells, with influx and efflux included at only the outermost shell. The concentration of the unbound form of the immobile buffer in every shell could be calculated from the bound form and the total concentration. For the results shown in Figure $6 A-E$, influx was set to zero and the equations were evaluated using initial conditions of $\left[\mathrm{Ca}^{2+}\right]=0$ everywhere except for $\left[\mathrm{Ca}^{2+}\right]=500 \mathrm{~nm}$ in the outermost shell and all reaction partners unbound. For the results in Figure $6 \mathrm{~F}$, initial values of $\left[\mathrm{Ca}^{2+}\right]$ and all bound reaction partners were zero, and a step influx of $3.3 \mathrm{~nm} / \mathrm{ms}$ was applied. For the results in Figure 7, voltage-sensitive calcium currents were represented as instantaneous functions of time, each with a sigmoidal voltage sensitivity of activation determined by the half-activation voltage $V_{\mathrm{H}}$ and the slope factor $V_{\mathrm{S}}$ (Table 1). The N-type channel was represented as a high-threshold channel that would only be activated by large depolarizations comparable to the action potential. The L-type $\left(\mathrm{Ca}_{\mathrm{V}} 1.3\right)$ channel had a half activation voltage of -40 $\mathrm{mV}$ and a slope factor of $10 \mathrm{mV}$ (Lipscombe et al., 2004). In addition to calcium concentration and bound RPs in each shell, we calculated integrated values of these by averaging the values across shells, weighted by the shell volumes. The integrated binding of calcium to the fast mobile buffer, for example, is an approximation to the signal that would be measured using a fast mobile calcium indicator, averaging across the volume of a cell compartment, as in our experiments.

In response to an impulse of calcium influx, the three-reaction partner equations yield a cascade of changes in calcium binding to each partner, determined by RP concentrations, on and off rates, diffusion coefficients, and calcium pump rate and affinity.
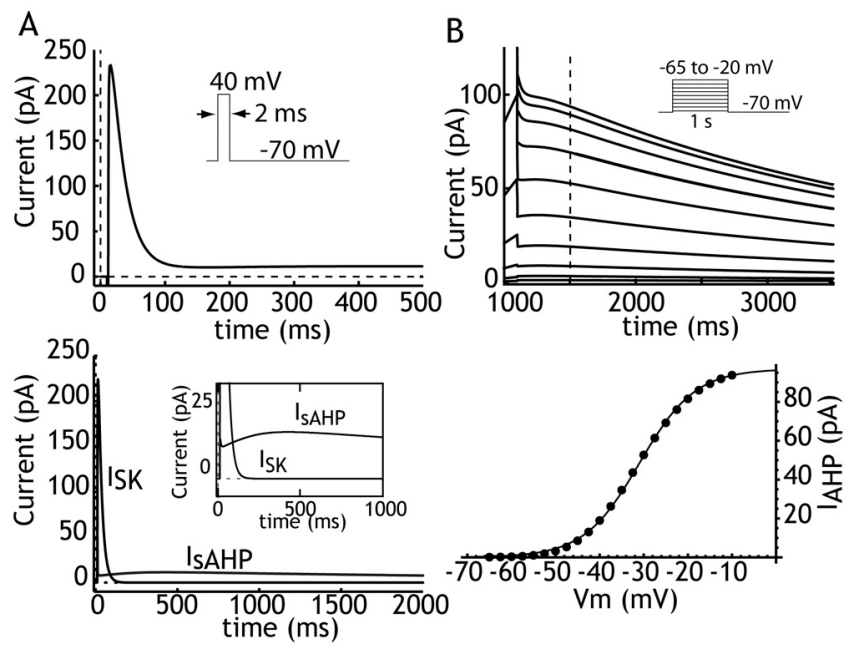

Figure 7. Currents evoked by brief and prolonged calcium transients. The model consists of calcium diffusion and reaction partners as in Figure 6, but with addition of high-threshold $\left(\mathrm{Ca}_{\mathrm{v}} 2\right)$ and low-threshold $\left(\mathrm{Ca}_{\mathrm{v}} 1.3\right)$ calcium currents and SK and SAHP currents triggered by binding of calcium to the SK and slow RP sites, respectively. $A$, After a brief pulse approximating an action potential, the high level of calcium binding to the high-affinity RP in the outermost shell produces a selective activation of SK current (compare with Fig. 6E). B, Activation curve obtained for the slow AHP after $1 \mathrm{~s}$ depolarizing steps. Measurement at $400 \mathrm{~ms}$ after offset of voltage pulse yields an activation curve like that seen for SAHP current in cholinergic interneurons.

For a wide range of values of these parameters, the sequence is qualitatively similar. Free calcium drops nearly to baseline levels almost immediately, as it binds to reaction partners in the outermost shell in proportion to their concentrations and on rates. At this time, the off rates (and so the affinities) of calcium binding sites are unimportant. Immediately afterward, calcium is redistributed from the fast but low-affinity fixed reaction partner to the fast but higher-affinity mobile one, and within a few milliseconds most calcium is bound to the high-affinity fast mobile RP. Initially, almost all calcium-bound fast high-affinity mobile RP is located in the shell immediately under the membrane, resulting in a high level of SK binding, but this decays rapidly by diffusion of the calcium-bound mobile RP. The decay of overall calcium binding to the fast mobile RP (which includes the decay of calcium binding to the calcium indicator) occurs mostly by transfer of calcium to the slow mobile RP. This step is slow compared with the diffusion of the fast RP, so the mobility of the slow highaffinity RP makes almost no contribution to the spatial redistribution of calcium, and binding to this RP is spatially uniform during the transient. If this binding site were made to be immobile, it would not alter the results. Ultimately, calcium binding is distributed among all the reaction partners according to their concentrations and affinities, and they decay at a shared rate, determined by the total calcium buffer load and the pump rate.

For purposes of selecting a particular set of values for the model parameters for the figures, we fixed the fast mobile RP using the known kinetics of calcium binding to bis-fura-2, set the concentration of this reaction partner at $100 \mu \mathrm{M}$ to approximate that obtained using calcium imaging experiments, and adjusted the on and off rates and concentration of the fast but low-affinity fixed buffer according to those measured by Neher and Augustine (1992) for chromaffin cells. The diffusion constant of free calcium was set at the diffusion coefficient of calcium in sea water and that for both mobile buffers was set to the diffusion coefficient for BAPTA (Wu et al., 1996). This left the concentration, on 
Table 1. Model parameters used for Figures 6 and 7

\begin{tabular}{|c|c|c|c|}
\hline Parameter & Value & Parameter & Value \\
\hline Diameter & 20 or $5(\mu \mathrm{m})$ & $\mathrm{BT}_{\mathrm{i}}$ & $1,000,000(\mathrm{~nm})$ \\
\hline$k_{\mathrm{p}}$ & $100(\mathrm{~nm})$ & $\alpha_{\mathrm{SK}}$ & $0.0004\left(\mathrm{~nm}^{-1} \cdot \mathrm{ms}^{-1}\right)$ \\
\hline$v_{\max }$ & $0.00025\left(\mathrm{nmol} \cdot \mathrm{cm}^{-2} \cdot \mathrm{ms}^{-1}\right)$ & $\beta_{\mathrm{SK}}^{\mathrm{SK}}$ & $0.2\left(\mathrm{nM}^{-1} \cdot \mathrm{ms}^{-1}\right)$ \\
\hline$D^{\ln a}$ & $6 \times 10^{-9}\left(\mathrm{~cm}^{2} / \mathrm{ms}\right)$ & $\mathrm{BT}_{\mathrm{SK}}$ & $5(\mathrm{~nm})$ \\
\hline$D_{\text {rp }}$ & $2 \times 10^{-9}\left(\mathrm{~cm}^{2} / \mathrm{ms}\right)$ & $E_{\mathrm{Ca}}{ }^{\mathrm{n}}$ & $100(\mathrm{mV})$ \\
\hline$\alpha_{\mathrm{f}}$ & $0.0004\left(\mathrm{~nm}^{-1} \cdot \mathrm{ms}^{-1}\right)$ & $V_{H N}$ & $20(\mathrm{mV})$ \\
\hline$\beta_{\mathrm{f}}$ & $0.2\left(\mathrm{~nm}^{-1} \cdot \mathrm{ms}^{-1}\right)$ & $V_{S N}$ & $10(\mathrm{mV})$ \\
\hline $\mathrm{BT}_{\mathrm{f}}$ & $100,000(\mathrm{~nm})$ & $V_{\mathrm{HL}}$ & $-40(\mathrm{mV})$ \\
\hline$\alpha_{\mathrm{s}}$ & $6 \times 10^{-6}\left(\mathrm{~nm}^{-1} \cdot \mathrm{ms}^{-1}\right)$ & $V_{S L}$ & $10(\mathrm{mV})$ \\
\hline$\beta_{\mathrm{s}}$ & $0.0012\left(\mathrm{~nm}^{-1} \cdot \mathrm{ms}^{-1}\right)$ & $g_{\mathrm{L}}$ & $0.2\left(\mathrm{mS} / \mathrm{cm}^{2}\right)$ \\
\hline $\mathrm{BT}_{5}$ & $200,000(\mathrm{~nm})$ & $g_{\mathrm{N}}$ & $20\left(\mathrm{mS} / \mathrm{cm}^{2}\right)$ \\
\hline$\alpha_{\mathrm{i}}$ & $0.0001\left(\mathrm{~nm}^{-1} \cdot \mathrm{ms}^{-1}\right)$ & $g_{\mathrm{SK}}$ & $5\left(\mathrm{mS} / \mathrm{cm}^{2}\right)$ \\
\hline$\beta_{\mathrm{i}}$ & $5\left(\mathrm{nM}^{-1} \cdot \mathrm{ms}^{-1}\right)$ & $g_{\mathrm{SAHP}}$ & $2\left(\mathrm{mS} / \mathrm{cm}^{2}\right)$ \\
\hline
\end{tabular}

and off rates of the slow mobile RP, and the rate of the transmembrane pump as free parameters. To determine those, we used the final slow decay time constant of all the buffers (including the calcium indicator) after a long-duration calcium current $(\sim 2 \mathrm{~s}$ as in Fig. 7), and the time constant of redistribution between the fast and slow high-affinity buffers ( $\sim 200 \mathrm{~ms}$, which we assume to be the time constant of the fast decay of calcium signal observed after an action potential as in Fig. 6). In addition, we searched for parameters that maximally separated the fast and slow transients, so that there was minimal slow component to the response to an impulse, and minimal fast component of the response to a long pulse, and that produced a difference in the size and decay time constant of both the fast and slow components depending on the compartment diameter, to correspond to the differences shown in Figure 4. The parameters obtained in this way are shown in Table 1.

The results for impulses and steps of calcium influx are shown in Figure $6 A-F$. The calcium delivered to the outermost shell by an impulse current was bound to the fast reaction partners within the outermost shell before any substantial diffusion could occur. The fixed low-affinity reaction partner contributed substantially to that binding in the first millisecond, but most of the calcium was transferred to the fast mobile buffer within $2-5 \mathrm{~ms}$ (Fig. $6 B$ ). Subsequently, calcium was transferred from the fast mobile RP to the slow high-affinity RP until they reached an equilibrium determined by their relative affinities. This transfer, which is associated with a reduction of calcium binding to the calcium indicator, occurred with a time constant of $\sim 200 \mathrm{~ms}$ (Fig. $6 C$ ). The influence of the slow reaction partner on the decay rate of the faster one can also be seen in Fig. 6C. When the slow RP was removed, the resulting integrated calcium transient had a single decay time constant greater than $500 \mathrm{~ms}$. The transmembrane pump rate for cholinergic cells is not known, and the use of a single pump rate and dissociation constant is a drastic simplification, as there are certainly several transmembrane calcium transport mechanisms differing in rate and affinities. Various models of calcium redistribution in neurons have used a wide range of pump rates, from $\sim 2 \mathrm{pmol} \cdot \mathrm{cm}^{-2} \cdot \mathrm{s}^{-1}$ (Nowycky and Pinter, 1993) to $\sim 75 \mathrm{pmol} \cdot \mathrm{cm}^{-2} \cdot \mathrm{s}^{-1}$ (Markram et al., 1998), and these are expected to represent not only transmembrane pumps and exchangers, but also uptake into intracellular stores. We used the difference in the time constant of bis-fura- 2 transients seen in the soma and dendrites of cholinergic interneurons after single action potentials to obtain a rough estimate of the effective speed of this composite cytoplasmic calcium removal process. For impulse changes in calcium, if the pump rate was too slow, it would not effectively compete with the slow reaction partner in the removal of calcium from bis-fura- 2 and the other fast reaction partners. In this case, the time constant of the fast transient (and conversely rise time of the slow AHP) was independent of diameter of the compartment. Our experimental results show that the decay of the action potential-triggered bisfura-2 transient was faster in the dendrites. Achieving this dependence of the decay of the single-spike transient on surfacearea-to-volume ratio in the model (Fig. 6D) thus required the presence of a fast (high $v_{\max }$ or high affinity) transmembrane pump.

Because nearly all calcium was bound to reaction partners, calcium diffused at a rate determined primarily by the diffusion of the reaction partners and the proportion of calcium bound to mobile reaction partners. In the first microseconds of the impulse response, a large proportion of calcium was bound to the fast immobile RP. The radial diffusion of calcium depended greatly on its acquisition by the fast mobile RP. Thus, there was initially a very steep gradient in the concentration of calcium-bound fast mobile RP (Fig. 6E). Assuming that the fast mobile RP diffuses at approximately the same rate as EGTA (as used here), this spatial gradient is very short lived for processes of diameters comparable to the cholinergic interneuron $(\leq 20 \mu \mathrm{m})$. Its time constant is much shorter than that of redistribution between the fast and slow mobile reaction partners. Thus, practically no spatial gradient developed in the binding to the slow mobile RP, and it could as well have been treated as immobile. The fast-decaying high spatial gradient of the fast reaction partner is of great significance, because it determines the time course of binding of calcium to the SK channel, which has similarly fast kinetics. This means that the calcium binding to the SK channel will be much larger and much briefer than that indicated by the spatially integrated signal from calcium indicator (Fig. 6E). After an impulse, the maximal binding to the slow RP (and controlling the slow AHP current) was a tiny fraction of the binding to the SK binding site (Fig. 6E).

At equilibrium, only the concentrations and affinities of reaction partners are important, and the relative calcium occupancy of all reaction partners (and all calcium indicators) is determined by those parameters. At that point, calcium binding to all reaction partners decays at the same rate, determined by the total buffer load and the pump rate (Neher and Augustine, 1992). This is the case in which calcium indicators are most useful in reflecting changes in free calcium, and calcium binding to all reaction partners. Achievement of equilibrium between calcium reaction partners is delayed by the time constants of redistribution described above. We simulated stepwise changes in calcium influx and the 
calcium occupancy of the slow and fast reaction partners during one such step are shown in Figure 6F. Under these influx conditions, only a small spatial gradient of the fast mobile RP was maintained during the step, the slow mobile RP binding was in spatial equilibrium throughout the transient. Total binding to the slow RP exceeded that of the faster RP, and the continuous transfer of calcium from the fast to the slow RP occurred throughout the pulse. Thus, the peak of calcium binding to the slow RP (and likewise for the sAHP current) occurred after the offset of the pulse, even when the pulse was very long. Except for the first $\sim 300 \mathrm{~ms}$, calcium binding to the slow RP was greater than that to the fast one, in contrast to the response to calcium impulses.

These differences in calcium binding to fast and slow RPs suggest large differences in the currents that would flow through calcium-dependent potassium currents controlled by these reaction partners, respectively. To estimate their impact on currents measured in our experiments, we simulated the response to brief or longer voltage-clamp pulses. We added two calcium currents, one activated only by very depolarized voltage pulses, similar to the $\mathrm{Ca}_{\mathrm{V}} 2$ (N-type) calcium channels in cholinergic neurons, and one by much more moderate depolarizations, as expected for the $\mathrm{Ca}_{\mathrm{V}} 1.3$ (L-type) calcium channel. Although these channels may differ in kinetics in ways that promote enhanced N-type activation during action potentials and L-type channel activation during slower pulses (Mermelstein et al., 2000), we did not include such kinetic differences in our simulations. If these were added, they would enhance the already very strong differential activation of the channels in the brief and long pulse conditions. Calcium binding to the SK sites in our model was briefer than the known kinetics of the SK channel (Hirschberg et al., 1998), and briefer than the SK current measured in our experiment. We therefore added a time constant of SK channel kinetics $\tau_{\mathrm{SK}}$, which, although much simpler than the biophysically accurate channel model presented by Hirschberg et al. (1998), had a similar exponential dependence on the concentration of calcium in the outermost shell.

The additional equations used for Figure 7 were as follows:

$$
\begin{gathered}
I_{\mathrm{L}}=\left(\frac{\overline{\mathrm{g}}_{\mathrm{L}}}{1+e^{-\left(\nu-V_{\mathrm{HL}}\right) / V_{\mathrm{SL}}}}\right)^{3}\left(\nu-E_{\mathrm{Ca}}\right) \\
I_{\mathrm{N}}=\left(\frac{\overline{\mathrm{g}}_{\mathrm{N}}}{1+e^{-\left(\nu-V_{\mathrm{HN}}\right) / V_{\mathrm{SN}}}}\right)^{3}\left(\nu-E_{\mathrm{Ca}}\right) \\
\frac{d(\mathrm{SK})}{d t}=\left(\mathrm{SK}_{\infty}-\mathrm{SK}\right) / \tau_{\mathrm{SK}} \\
I_{\mathrm{SK}}=\bar{g}_{\mathrm{SK}} \times \mathrm{SK}^{4} \times\left(\nu-\mathrm{E}_{\mathrm{K}}\right) \\
I_{\mathrm{SAHP}}=\bar{g}_{\mathrm{SAHP}} \times \frac{[\mathrm{BCa}]_{\mathrm{s}}}{[\mathrm{BCa}]_{\mathrm{s}}+[\mathrm{B}]_{\mathrm{S}}} \times\left(\nu-E_{\mathrm{K}}\right),
\end{gathered}
$$

in which sk is the proportion of total SK sites bound by calcium, and $[\mathrm{BCa}]_{s}$ and $[\mathrm{B}]_{s}$ are the concentrations of bound and unbound slow RP in the outermost shell.

The results are shown in Figure 7. A brief pulse to $+40 \mathrm{mV}$ from a holding potential of $-70 \mathrm{mV}$ triggers activation of both $\mathrm{L}$ and $\mathrm{N}$ currents, but only briefly. Because the maximal $\mathrm{N}$ current is much larger than $\mathrm{L}$, most calcium enters through this channel, making the calcium entering during brief pulses very sensitive to blockade of that current. The selectivity of SK channel activation by brief pulses is not caused by a special preference for calcium from $\mathrm{N}$ channels, but only by the brief nature of the calcium entry
(Fig. 7A). Similarly, long low-voltage pulses (Fig. 7B) selectively activate the lower-threshold $\left(\mathrm{Ca}_{\mathrm{V}} 1.3\right)$ L-type channels (e.g., Lipscombe et al., 2004), but the preferential activation of the slow AHP by these pulses is due to the prolonged nature of calcium entry. As in Figure $6 F$, the peak slow AHP current occurs after the offset of the current pulse.

\section{Discussion}

\section{Cholinergic cells have two $\mathrm{Ca}^{2+}$-dependent oscillations that differ in timescale}

The separation of timescales responsible for single spiking versus rhythmic bursting arises from the difference in both rise and decay rates of the single spike mAHP and the burst sAHP, both of which are $\mathrm{Ca}^{2+}$-dependent $\mathrm{K}^{+}$currents. This difference produces rhythmic oscillations of different frequency. The slow oscillation occurs at frequencies slower than $1 \mathrm{~Hz}$, whereas rhythmic single spiking is $3-10 \mathrm{~Hz}$. Although one of these mechanisms dominates autonomous firing at any one time, we have shown that both mechanisms can be demonstrated in all cholinergic cells at all times. Even in regularly firing neurons, depolarizing steps could produce slowly rising and slowly decaying changes in intracellular $\mathrm{Ca}^{2+}$, and sAHPs. These changes in $\mathrm{Ca}^{2+}$ were smaller, but still present, after action potentials were blocked using TTX. The two $\mathrm{Ca}^{2+}$-dependent $\mathrm{K}^{+}$currents responsible for the two timescales are relatively independent, relying on $\mathrm{Ca}^{2+}$ entering the cell through different kinds of $\mathrm{Ca}^{2+}$ channels. No sAHP current was detected after single action potentials despite the demonstration of large (but brief) increases in cytoplasmic $\mathrm{Ca}^{2+}$. Sustained $\mathrm{Ca}^{2+}$ currents evoke the sAHP, but not SK current, especially when small and triggered at voltages well below the action potential threshold (Wilson and Goldberg, 2006). Without this degree of independence of slow and fast $\mathrm{Ca}^{2+}$ currents and corresponding $\mathrm{Ca}^{2+}$-dependent $\mathrm{K}^{+}$currents, it would be impossible for the cell to generate two discretely different autonomous firing patterns.

\section{The time course of slow and medium afterhyperpolarization currents}

There are several ways that $\mathrm{Ca}^{2+}$-dependent $\mathrm{K}^{+}$currents could exhibit different timescales, but most of them do not predict correspondingly different timescales of calcium signals. The bestknown mechanism is diffusion distance, and it is known to contribute to the differences in kinetics of BK and SK currents. BK channels have a lower $\mathrm{Ca}^{2+}$ affinity than SK currents, and are located closer to voltage-gated $\mathrm{Ca}^{2+}$ channels (Marty and Neher, 1985; Sah, 1992; Marrion and Tavalin, 1998; Müller et al., 2007). $\mathrm{BK}$ channels are activated during $\mathrm{Ca}^{2+}$ influx, when a high concentration of $\mathrm{Ca}^{2+}$ is present within a few nanometers of the channels, and they deactivate rapidly when $\mathrm{Ca}^{2+}$ influx stops, although the average $\mathrm{Ca}^{2+}$ concentration in the cell is at its peak. SK channels are sensitive to the $\mathrm{Ca}^{2+}$ within a thin layer adjacent to the plasma membrane. $\mathrm{A} \mathrm{Ca}^{2+}$ transient associated with an action potential can produce very rapid and brief activation of BK and slower but more prolonged activation of SK neurons in the same cell (e.g., Faber and Sah, 2002), including in striatal cholinergic interneurons (Bennett et al., 2000; Goldberg and Wilson, 2005). For a similar mechanism to produce the difference in time course between the SK current and the sAHP current, the $\mathrm{Ca}^{2+}$ sensor for the latter would have to be located far from the site of $\mathrm{Ca}^{2+}$ entry. Studies of other neurons have not supported a causal role of $\mathrm{Ca}^{2+}$ diffusion in the kinetics of the sAHP. For example, the temperature sensitivity of sAHP kinetics is greater than expected for diffusion (Sah and McLachlan, 1991; Lee et al., 2005). 
Use of flash photolysis to release $\mathrm{Ca}^{2+}$ in the cytoplasm has produced mixed results, giving a rapid onset of current consistent with a long diffusion distance in one study (Lancaster and Zucker, 1994) and a slow current onset inconsistent with a long diffusion distance in another (Sah and Clements, 1999).

The sAHP channel could acquire its kinetics from slow channel gating (Hocherman et al., 1992; Sah and Clements, 1999) or a slow intermediate step between $\mathrm{Ca}^{2+}$ binding and channel gating (Schwindt et al., 1992; Jahromi et al., 1999). Sah and Isaacson (1995) used noise analysis to estimate sAHP channel mean open time at only $2 \mathrm{~ms}$, much too short to account for the onset kinetics of the current. There probably is an intermediate step in activation of the sAHP current but it is unknown whether or not it is slow. In hippocampal neurons, the $\mathrm{Ca}^{2+}$ sensor for the slow AHP has been associated with the cytoplasmic protein hippocalcin (Tzingounis et al., 2007), which must bind to the cell membrane to have efficacy. The kinetic properties of $\mathrm{Ca}^{2+}$ binding to hippocalcin are not yet known, and so it is not certain whether the slow step is associated with $\mathrm{Ca}^{2+}$ binding, diffusion of hippocalcin, or its interaction with the $\mathrm{K}^{+}$channel.

All of the above mechanisms generate a slow $\mathrm{Ca}^{2+}$-dependent $\mathrm{K}^{+}$current from a single faster $\mathrm{Ca}^{2+}$ transient, but none predicts that $\mathrm{Ca}^{2+}$ concentrations measured with a standard indicator would show two timescales corresponding to two different $\mathrm{K}^{+}$ currents, as seen here. A mechanism that relies on different $\mathrm{Ca}^{2+}$ removal rates could be constructed if $\mathrm{Ca}^{2+}$ concentration changed at different rates on different parts of the cell. For example, spike-triggered $\mathrm{Ca}^{2+}$ transients are usually larger and briefer in the dendrites than in the somata of neurons, because of the higher surface-area-to-volume ratio of the dendrites. If SK currents were preferentially located in the fine dendrites of the cholinergic neuron, and the slow AHP current in the large somatic compartment, this could produce different timescales for the two currents, but that would be evident in the comparison of somatic and dendritic $\mathrm{Ca}^{2+}$ transients. This mechanism predicts that $\mathrm{Ca}^{2+}$ decay rates would be consistent at any one part of the dendritic field, and that there would be very large differences in decay rates in different parts of the cell. Jahromi et al. (1999) eliminated this mechanism for hippocampal neurons, and our results also do not support this view. $\mathrm{Ca}^{2+}$ decayed at two different rates for slow and for brief $\mathrm{Ca}^{2+}$ transients in all parts of the neuron. The difference between the somata and dendrites was only a factor of 2-3, and did not correspond to the time course of slow and medium AHP currents.

In the past, slow $\mathrm{Ca}^{2+}$ binding to its sensor was not considered a likely candidate as the rate-limiting step in sAHP current activation, because the time to onset of the current was insensitive to $\mathrm{Ca}^{2+}$ concentration (Sah and Clements, 1999; Gerlach et al., 2004). This argument is compelling if the sAHP $\mathrm{Ca}^{2+}$ binding site has direct access to cytoplasmic $\mathrm{Ca}^{2+}$ with a time course determined only by $\mathrm{Ca}^{2+}$ entry. However, the presence of other $\mathrm{Ca}^{2+}$ binding sites with faster binding kinetics can shape the time course of $\mathrm{Ca}^{2+}$ available to bind the sAHP sensor. The kinetics of the various RPs, not the rate of $\mathrm{Ca}^{2+}$ entry to the cell, will determine the delivery of $\mathrm{Ca}^{2+}$ to the sAHP site. Because the indicator used to track cytoplasmic $\mathrm{Ca}^{2+}$ is a participant in the interaction, its reporting of $\mathrm{Ca}^{2+}$ concentration provides a window on this process in the form of a difference in apparent $\mathrm{Ca}^{2+}$ decay rates of fast vs slow $\mathrm{Ca}^{2+}$ transients. Our results provide evidence that the temporal properties of the SAHP in striatal cholinergic interneurons, including the delay in its onset and its slow decay, are caused by the kinetics of the sAHP $\mathrm{Ca}^{2+}$ binding site, interacting with alternate binding sites in the cytoplasm. This explanation is con- sistent with the results of previous studies in other neuron types, and with other properties of the SAHP current, including its sensitivity to fast and slow exogenous buffers and its insensitivity to brief $\mathrm{Ca}^{2+}$ transients. It should be noted that in some cells, sAHPs can be triggered from single action potentials, but in those cases single action potentials often release calcium from intracellular stores, thereby creating a prolonged calcium transient (e.g., Sah and McLachlan, 1991). Thus, the mechanism of the sAHP in these cells could still result from slow kinetics at the calcium binding site.

\section{Bursting and irregular firing patterns in cholinergic interneurons}

The autonomous firing of striatal cholinergic neurons is largely governed by $\mathrm{Ca}^{2+}$-dependent $\mathrm{K}^{+}$currents. During regular firing, SK currents triggered by individual action potentials produce brief afterhyperpolarization currents that regularize firing and regulate the response of the oscillatory period to brief synaptic inputs (Bennett and Wilson, 1998; Bennett et al., 2000). The calcium activating the SK current enters the cell via $\omega$-conotoxinGVIA-sensitive channels that are triggered almost exclusively by action potentials. In all cholinergic neurons, a slowly varying background of calcium entering the cell via dihydropyridinesensitive calcium channels is also present, but does not contribute to the SK current. Instead, calcium from this source controls selectively a slower $\mathrm{Ca}^{2+}$-dependent $\mathrm{K}^{+}$current. Because of the delay between calcium influx and activation of the $\mathrm{Ca}^{2+}$ dependent $\mathrm{K}^{+}$current, this slow one tends to promote bursting and pausing. These two $\mathrm{K}^{+}$currents, both controlled by calcium influx and having opposite effects on firing pattern, are activated selectively by different $\mathrm{Ca}^{2+}$ currents and so are subject to differential control by neuromodulators that affect $\mathrm{Ca}_{\mathrm{V}} 2$ and $\mathrm{Ca}_{\mathrm{V}} 1$ channels differently (Yan et al., 1997; Pisani et al., 2000; CabreraVera et al., 2004). We have shown that this specificity of $\mathrm{Ca}^{2+}$ dependent $\mathrm{K}^{+}$channels in cholinergic neurons is not associated with any spatial organization of channels on the cells, but rather may arise from the kinetics of calcium binding.

\section{References}

Abel HJ, Lee JCF, Callaway JC, Foehring RC (2004) Relationships between intracellular calcium and afterhyperpolarizations in neocortical pyramidal neurons. J Neurophysiol 91:324-335.

Aghajanian GK, Rasmussen K (1989) Intracellular studies in the facial nucleus illustrating a simple new method for obtaining viable motoneurons in adult rat brain slices. Synapse 3:331-338.

Atluri PP, Regehr WG (1996) Determinants of the time course of facilitation at the granule cell to Purkinje cell synapse. J Neurosci 16:5661-5671.

Bennett BD, Wilson CJ (1998) Synaptic regulation of action potential timing in neostriatal cholinergic interneurons. J Neurosci 18:8539-8549.

Bennett BD, Wilson CJ (1999) Spontaneous activity of neostriatal cholinergic interneurons in vitro. J Neurosci 19:5586-5596.

Bennett BD, Callaway JC, Wilson CJ (2000) Intrinsic membrane properties underlying spontaneous tonic firing in neostriatal cholinergic interneurons. J Neurosci 20:8493-8503.

Cabrera-Vera TM, Hernandez S, Earls LR, Medkova M, Sundgren-Andersson AK, Surmeier DJ, Hamm HE (2004) RGS9-2 modulates D2 dopamine receptor-mediated $\mathrm{Ca} 2+$ channel inhibition in rat striatal cholinergic interneurons. Proc Natl Acad Sci U S A 101:16339-16344.

Ermentrout B (2002) Simulating, analyzing, and animating dynamical systems: a guide to XPPAUT for researchers and students. Philadelphia: SIAM.

Faber ES, Sah P (2002) Physiological role of calcium-activated potassium currents in the rat lateral amygdala. J Neurosci 22:1618-1628.

Feller MB, Delaney KR, Tank DW (1996) Presynaptic calcium dynamics at the frog retinotectal synapse. J Neurophysiol 76:381-400.

Gerlach AC, Maylie J, Adelman JP (2004) Activation kinetics of the slow 
afterhyperpolarization in hippocampal CA1 neurons. Pflugers Arch 448:187-196.

Goldberg JA, Wilson CJ (2005) Control of spontaneous firing patterns by the selective coupling of calcium currents to calcium activated potassium currents in striatal cholinergic interneurons. J Neurosci 25:10230-10238.

Hirschberg B, Maylie J, Adelman JP, Marrion NV (1998) Gating of recombinant small-conductance Ca-activated $\mathrm{K}+$ channels by calcium. J Gen Physiol 111:565-581.

Hocherman SD, Werman R, Yarom Y (1992) An analysis of the long-lasting after-hyperpolarization of guinea-pig vagal motoneurones. J Physiol 456:325-349.

Jahromi BS, Zhang L, Carlen PL, Pennefather P (1999) Differential timecourse of slow afterhyperpolarizations and associated $\mathrm{Ca} 2+$ transients in rat CA1 pyramidal neurons: further dissociation by $\mathrm{Ca} 2+$ buffer. Neuroscience 88:719-726.

Lancaster B, Zucker RS (1994) Photolytic manipulation of Ca2+ and the time course of slow, $\mathrm{Ca}(2+)$-activated $\mathrm{K}+$ current in rat hippocampal neurones. J Physiol 475:229-239.

Lee JCF, Callaway JC, Foehring RC (2005) Effects of temperature on calcium transients and $\mathrm{Ca} 2+$-dependent afterhyperpolarizations in neocortical pyramidal neurons. J Neurophysiol 93:2012-2020.

Lipscombe D, Helton TD, Xu W (2004) L-type calcium channels: the low down. J Neurophysiol 92:2633-2641.

Markram H, Roth A, Helmchen F (1998) Competitive calcium binding: implications for dendritic calcium signaling. J Comput Neurosci 5:331-348.

Marrion NV, Tavalin SJ (1998) Selective activation of Ca2+-activated K+ channels by co-localized $\mathrm{Ca} 2+$ channels in hippocampal neurons. Nature 395:900-905.

Marty A, Neher E (1985) Potassium channels in cultured bovine adrenal chromaffin cells. J Physiol 367:117-141.

Mermelstein PG, Bito H, Deisseroth K, Tsien RW (2000) Critical dependence of cAMP response element-binding protein phosphorylation on L-type calcium channels supports a selective response to EPSPs in preference to action potentials. J Neurosci 20:266-273.

Müller A, Kukley M, Uebachs M, Beck H, Dietrich D (2007) Nanodomains of single $\mathrm{Ca}^{2+}$ channels contribute to action potential repolarization in cortical neurons. J Neurosci 27:483-495.

Naraghi M, Müller TH, Neher E (1998) Two-dimensional determination of the cellular $\mathrm{Ca} 2+$ binding in bovine chromaffin cells. Biophys J 75:1635-1647.

Neher E, Augustine GJ (1992) Calcium gradients and buffers in bovine chromaffin cells. J Physiol 450:273-301.

Nowycky MC, Pinter MJ (1993) Time courses of calcium and calcium- bound buffers following calcium influx in a model cell. Biophys 64:77-91.

Pisani A, Bonsi P, Centonze D, Calabresi P, Bernardi G (2000) Activation of D2-like dopamine receptors reduces synaptic inputs to striatal cholinergic interneurons. J Neurosci 20:RC69.

Raz A, Feingold A, Zelanskaya V, Vaadia E, Bergman H (1996) Neuronal synchronization of tonically active neurons in the striatum of normal and parkinsonian primates. J Neurophysiol 76:2083-2088.

Sah P (1992) Role of calcium influx and buffering in the kinetics of Ca2+activated $\mathrm{K}+$ current in rat vagal motoneurons. J Neurophysiol 68:2237-2247.

Sah P, Clements JD (1999) Photolytic manipulation of $\left[\mathrm{Ca}^{2+}\right]_{\mathrm{i}}$ reveals slow kinetics of potassium channels underlying the afterhyperpolarization in hippocampal pyramidal neurons. J Neurosci 19:3657-3664.

Sah P, Isaacson JS (1995) Channels underlying the slow afterhyperpolarization in hippocampal pyramidal neurons: neurotransmitters modulate the open probability. Neuron 15:435-441.

Sah P, McLachlan EM (1991) Ca(2+)-activated K+ currents underlying the afterhyperpolarization in guinea pig vagal neurons: a role for $\mathrm{Ca}(2+)$ activated $\mathrm{Ca} 2+$ release. Neuron 7:257-264.

Schwindt PC, Spain WJ, Crill WE (1992) Effects of intracellular calcium chelation on voltage-dependent and calcium-dependent currents in cat neocortical neurons. Neuroscience 47:571-578.

Teagarden M, Atherton JF, Bevan MD, Wilson CJ (2008) Accumulation of cytoplasmic calcium, but not apamin-sensitive afterhyperpolarization current, during high frequency firing in rat subthalamic nucleus cells. J Physiol 586:817-833.

Tzingounis AV, Kobayashi M, Takamatsu K, Nicoll RA (2007) Hippocalcin gates the calcium activation of the slow afterhyperpolarization in hippocampal pyramidal cells. Neuron 53:487-493.

Wagner J, Keizer J (1994) Effects of rapid buffers on Ca2+ diffusion and $\mathrm{Ca} 2+$ oscillations. Biophys J 67:447-456.

Wilson CJ (2005) The mechanism of intrinsic amplification of hyperpolarizations and spontaneous bursting in striatal cholinergic interneurons. Neuron 45:575-585.

Wilson CJ, Goldberg JA (2006) Origin of the slow afterhyperpolarization and slow rhythmic bursting in striatal cholinergic interneurons. J Neurophysiol 95:196-204.

Wu YC, Tucker T, Fettiplace R (1996) A theoretical study of calcium microdomains in turtle hair cells. Biophys J 71:2256-2275.

Zan Z, Song WJ, Surmeier DJ (1997) D2 dopamine receptors reduce N-type $\mathrm{Ca} 2+$ currents in rat neostriatal cholinergic interneurons through a membrane-delimited, protein-kinase-C-insensitive pathway. J Neurophysiol 77:1003-1015. 